\title{
Modelos didáticos de DNA no ensino de genética: experiência com estudantes do ensino médio em uma escola pública do Piauí
}

\author{
DNA didactic models in genetics teaching: experience with high school students in a public school \\ in Piauí
}

Modelos didácticos de ADN en la enseñanza de la genética: experiencia con estudiantes de secundaria en una escuela pública en Piauí

\author{
Junielson Soares da Silva \\ ORCID: https://orcid.org/0000-0003-4872-2355 \\ Secretaria de Educação do Piauí, Brasil \\ E-mail: junielsonbio10@gmail.com \\ Neyla Cristiane Rodrigues de Oliveira \\ ORCID: https://orcid.org/0000-0003-0904-8580 \\ Universidade Federal do Piauí, Brasil \\ E-mail: neylacristiane_bio@yahoo.com \\ Fabrício Soares de Sousa \\ ORCID: https://orcid.org/0000-0001-8293-8892 \\ Secretaria de Educação do Piauí, Brasil \\ E-mail: sousa.f.s@hotmail.com \\ Cícero Quirino da Silva Neto \\ ORCID: https://orcid.org/0000-0003-0414-3036 \\ Secretaria de Educação do Piauí, Brasil \\ E-mail: cquirino07@gmail.com \\ Espedito de Sousa Saraiva \\ ORCID: https://orcid.org/0000-0002-6735-2591 \\ Secretaria de Educação do Mato Grosso do Sul, Brasil \\ E-mail: espeditto_00@hotmail.com \\ Marilha Vieira de Brito \\ https://orcid.org/0000-0002-6658-2264 \\ Universidade Federal do Piauí, Brasil \\ E-mail: marilhabio@hotmail.com \\ Gisele Holanda de Sá \\ ORCID: https://orcid.org/0000-0002-0687-9314 \\ Universidade Federal do Piauí, Brasil \\ E-mail: giselehollanda2@gmail.com \\ Layane Valéria Amorim \\ ORCID: https://orcid.org/0000-0002-0412-0750 \\ Universidade Federal do Piauí, Brasil \\ E-mail: layane.valeria@hotmail.com
}

\begin{abstract}
Resumo
A genética é uma das áreas da Biologia considerada de difícil aprendizagem pelos alunos, devido à presença de termos complexos e do distanciamento com o cotidiano dos estudantes. Nesse sentido, objetivou-se descrever o uso de modelos didáticos de DNA, confeccionados por alunos da $3^{\text {a }}$ série do Ensino Médio, de uma escola pública do Piauí, para abordar conceitos básicos de genética. A pesquisa possui natureza qualitativa e foi realizada com 34 alunos da $3^{\text {a }}$ série do Ensino Médio da Unidade Escolar Saturnino Moura, localizada em São Félix do Piauí. Para coleta de dados, utilizou-se um questionário semiestruturado, observações e registros em Diário de Bordo dos pesquisadores. Constatou-se que os estudantes se sentiram motivados durante a confecção dos modelos didáticos de DNA, demonstrando a relevância de sua aplicação nas aulas de Biologia e no desenvolvendo do trabalho em equipe. Além disso, constatou-se que somente a aula expositiva teórica não constitui uma metodologia eficaz para a aprendizagem dos assuntos de genética. Sendo importante, portanto, a utilização de metodologias ativas como: a construção e aplicação dos modelos didáticos, nos quais os alunos participam ativamente e tornam-se mediadores do próprio conhecimento. Assim, esses modelos representam instrumentos sugestivos e podem contribuir no processo de ensinoaprendizagem de conteúdos abstratos e de difícil abordagem nas aulas de Biologia.
\end{abstract}

Palavras-chave: Biologia; Educação básica; Ensino-aprendizagem; Metodologias ativas. 


\begin{abstract}
Genetics is one of the areas of Biology considered difficult for students to learn, due to the presence of complex terms and the distance from students' daily lives. In this sense, the objective was to describe the use of didactic models of DNA, made by students of the 3rd grade of High School, from a public school in Piauí, to address basic concepts of genetics. The research has a qualitative nature and was carried out with 34 students of the 3rd grade of High School at the Saturnino Moura School Unit, located in São Félix do Piauí. For data collection, a semi-structured questionnaire, observations and records in the researchers' logbook were used. It was found that students felt motivated during the making of didactic models of DNA, demonstrating the relevance of its application in Biology classes and the development of teamwork. In addition, it was found that only the theoretical lecture does not constitute an effective methodology for learning the subjects of genetics. Therefore, it is important to use active methodologies, such as the construction and application of didactic models, in which students actively participate and become mediators of their own knowledge. Thus, these models represent suggestive instruments and can contribute to the teaching-learning process of abstract contents that are difficult to approach in Biology classes.
\end{abstract}

Keywords: Biology; Basic education; Teaching-learning; Active methodologies.

\title{
Resumen
}

La genética es una de las áreas de la Biología que se considera de difícil aprendizaje para los estudiantes, debido a la presencia de términos complejos y la distancia con la vida cotidiana de los estudiantes. En este sentido, el objetivo fue describir el uso de modelos didácticos de $\mathrm{ADN}$, realizados por estudiantes de 3er grado de Bachillerato, de una escuela pública de Piauí, para abordar conceptos básicos de genética. La investigación tiene un carácter cualitativo y se llevó a cabo con 34 estudiantes del 3er grado de Bachillerato de la Unidad Escolar Saturnino Moura, ubicada en São Félix do Piauí. Para la recolección de datos se utilizó un cuestionario semiestructurado, observaciones y registros en el diario de los investigadores. Se encontró que los estudiantes se sintieron motivados durante la elaboración de modelos didácticos de ADN, demostrando la relevancia de su aplicación en las clases de Biología y el desarrollo del trabajo en equipo. Además, se encontró que solo la lección teórica no constituye una metodología eficaz para el aprendizaje de las asignaturas de genética. Por tanto, es importante utilizar metodologías activas, como la construcción y aplicación de modelos didácticos, en las que los estudiantes participan activamente y se convierten en mediadores de su propio conocimiento. Así, estos modelos representan instrumentos sugerentes y pueden contribuir al proceso de enseñanza-aprendizaje de contenidos abstractos de difícil abordaje en las clases de Biología.

Palabras clave: Biología; Educación básica; Enseñanza-aprendizaje; Metodologías activas.

\section{Introdução}

A genética desperta a atenção dos educandos por tratar de tópicos científicos relacionados nas mídias, como: os transgênicos, terapia gênica, aconselhamento genético, sequenciamento de DNA, testes de paternidade, genética forense, dentre outros (Santana, Souza \& Sampaio, 2017). No entanto, seus conceitos na ausência de transposição didática e, de estratégias de ensino adequadas, se tornam de difícil aprendizagem, devido aos termos complexos e, do distanciamento com o cotidiano dos alunos (Corazza-Nunes et al., 2006).

Para Silva \& Saraiva (2020), é importante a realização de atividades escolares que utilizem metodologias didáticas que tornam o aluno protagonista do processo de aprendizagem. Nessa perspectiva, Lima et al. (2020) destacam que a Sequência de Ensino Investigativa (SEI), envolvendo Modelos Didáticos (MD), possibilita maior participação dos estudantes, podendo melhorar as relações aluno-aluno e aluno-professor. Assim, os MD são instrumentos sugestivos e representativos que podem ser eficazes na prática docente para o ensino de conteúdos abstratos, de forma a facilitar a aprendizagem, principalmente dos assuntos de genética, que são de difícil assimilação pelos discentes da educação básica (Larentis, Amancio \& Ghisi, 2020).

Com o desenvolvimento de novas tecnologias, a genética e, consequentemente, o ensino, passam por transformações. Dessa forma, o processo educativo deve ser atualizado, com a utilização de metodologias ativas e recursos didáticos que proporcionam ao discente o estímulo necessário à pesquisa e à busca por conhecimentos. Para isso, os professores podem promover atividades práticas e experimentais, além da construção e aplicação de MD, confeccionados com materiais de baixo custo, de fácil acesso e manuseio em sala de aula (Silva, 2018; Rezende \& Gomes, 2018; Nascimento et al., 2020).

Diante das dificuldades que os estudantes têm em compreender e assimilar os conteúdos de genética, com as situações concretas do cotidiano, bem como a importância em oportunizar o uso de instrumentos didáticos que fomentem aprendizagens 
significativas neste campo, objetivou-se descrever o uso de MD de DNA, confeccionados por alunos da $3^{\text {a }}$ série do Ensino Médio, de uma escola pública do Piauí, para abordar conceitos básicos de genética.

\section{Material e Métodos}

\subsection{Caracterização da pesquisa}

O presente estudo trata-se de uma pesquisa de campo qualitativa observacional, que se caracteriza por investigações em que, além da pesquisa bibliográfica e/ou documental, realiza coleta de dados junto a pessoas com o recurso de diferentes tipos de pesquisa (Fonseca, 2002; Pereira et al., 2018). Na pesquisa qualitativa, busca-se analisar os fatos, em seu ambiente de ocorrência e a observação constitui-se mecanismo para a pesquisa empírica (Florência \& Oliveira, 2019).

\subsection{Aspectos éticos legais}

Como amparo legal, utilizou-se a Resolução n ${ }^{\circ}$ 510, de 07 de abril de 2016, além dos regimentos e atribuições legais da Lei $\mathrm{n}^{\circ} 8.080$, de 19 de setembro de 1990, Lei $\mathrm{n}^{\circ}$ 8.142, de 28 de dezembro de 1990, pelo Decreto ${ }^{\circ}$ 5.839, de 11 de julho de 2006, que versam sobre a ética em pesquisa com seres humanos (Brasil, 2016). Para isso, foi esclarecido aos participantes a justificativa, objetivos, métodos e os benefícios do estudo. Evidenciou-se os direitos aos participantes da pesquisa e informação de que poderiam desistir do estudo a qualquer momento, sem prejuízos. Contudo, por tratar-se de uma metodologia didática a qual os discentes não estavam acostumados, todos estavam empolgados e optaram por participar. Sendo assim, os participantes foram convidados a assinar o Termo de Consentimento Livre e Esclarecido (TCLE).

\subsection{Local da pesquisa e público-alvo}

O trabalho foi realizado na Unidade Escolar Saturnino Moura, localizada na cidade de São Félix do Piauí, a 158 km da capital Teresina, Piauí. A turma era composta por 34 alunos da $3^{a}$ série do Ensino Médio. A atividade foi desenvolvida para abordar conceitos relacionados ao material genético, necessários para compreender os conteúdos da Primeira e Segunda Leis de Mendel, Mutações Cromossômicas, entre outros. Tendo em vista que os alunos têm dificuldade para lembrar dos termos trabalhados em anos anteriores.

\subsection{Percurso metodológico}

Os discentes foram organizados em seis grupos. Durante duas aulas, confeccionaram MD da molécula de DNA, com materiais de baixo custo: fita isolante, palito de picolé, balinhas de cores diversas, jujuba, arame, isopor, tinta guache, dentre outros. Feito isso, buscou-se relembrar alguns conceitos, como a diferença entre DNA e RNA, local do DNA na célula, bases nitrogenadas, nucleotídeo, gene, etc. Cada grupo deveria explicar os conceitos supracitados para um grupo de alunos da $1^{\mathrm{a}}$ série do Ensino Médio da escola. Uma vez que alguns desses termos são normalmente abordados em Citologia no $1^{\circ}$ volume do livro didático de Biologia. Após a atividade, aplicou-se um questionário semiestruturado com cinco questões para verificar a opinião dos estudantes sobre a atividade.

\section{Resultados}

Cada grupo confeccionou um MD de DNA (Figura 1), que foi utilizado para trabalhar a diferença entre DNA e RNA, local do DNA nas células, bases nitrogenadas, nucleotídeos, genes, cromossomos, dentre outros conceitos que são abordados na $1^{\text {a }}$ série do Ensino Médio (Lopes \& Rosso, 2012; 2013). Observou-se que os alunos apresentaram dificuldades com os conceitos supracitados. Tal situação pode comprometer a aprendizagem dos estudantes nos conteúdos de genética, bem como seu interesse pela área. Isso provavelmente está relacionado com o fato desta ser geralmente considerada, por grande parte dos 
discentes, a área mais complexa da Biologia na educação básica.

Figura 1 - Modelos didáticos da estrutura do DNA, produzido pelos alunos da $3^{\text {a }}$ série do Ensino Médio, da Unidade Escolar Saturnino Moura.
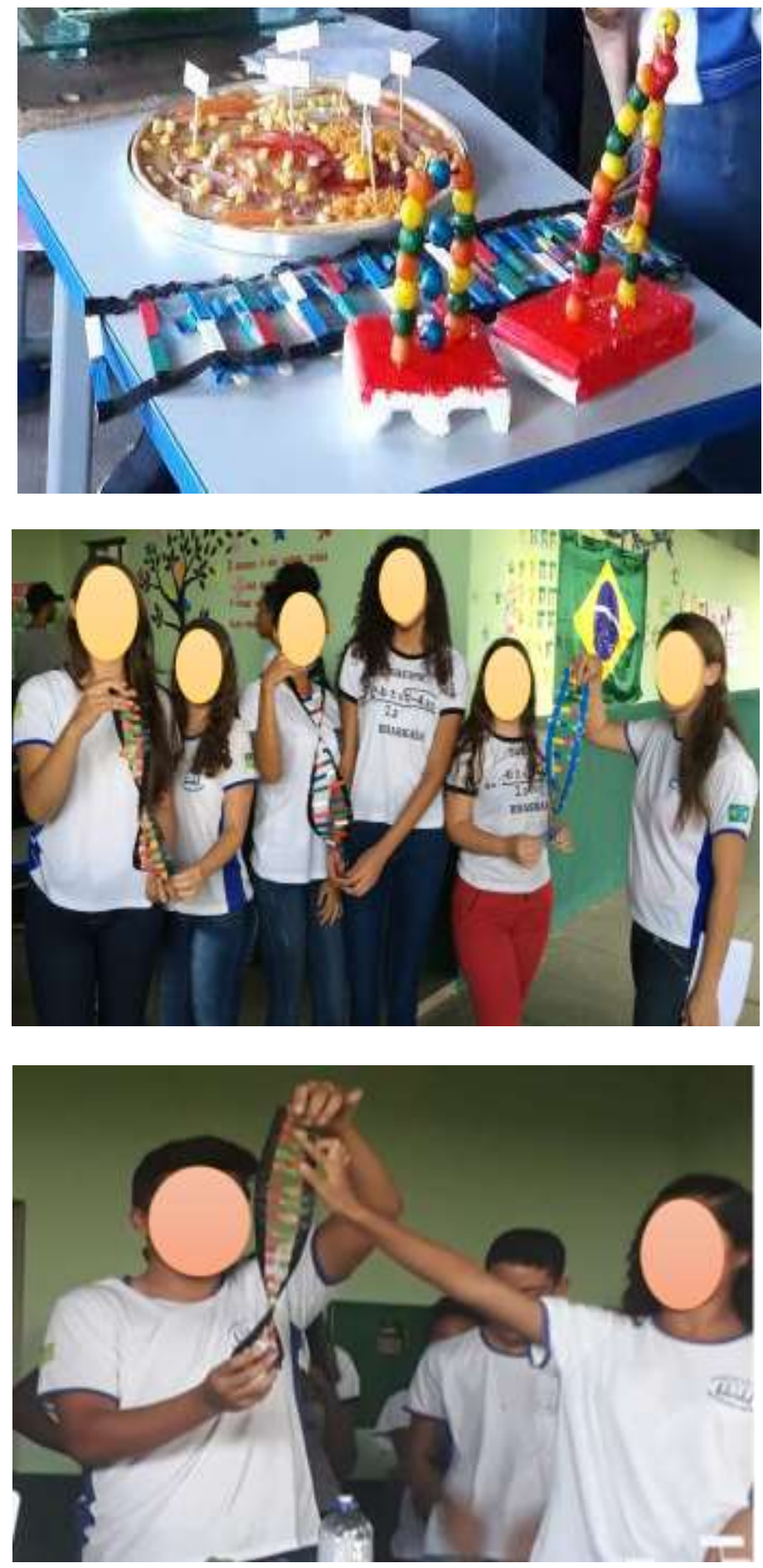

Fonte: Autores (2020).

Quando os estudantes foram questionados sobre a localização da molécula de DNA nas células eucariontes, constatou-se que parte representativa deles estavam cientes que o material genético se encontra no núcleo, envolvido pela membrana nuclear ou carioteca. Todavia, desconheciam a existência do DNA materno ou mitocondrial, que está presente nas mitocôndrias, organelas presentes no citoplasma da célula reprodutora materna. Ao questionar a diferença entre as moléculas 
de DNA e RNA, poucos alunos sabiam que estas eram compostas por fita dupla e fita simples, respectivamente, mas reconhecem a relação do DNA com a hereditariedade.

Sobre as bases nitrogenadas do DNA (Adenina, Timina, Citosina, Guanina) e do RNA (Uracila), muitos alunos não lembravam desses termos, demonstrando estranheza com as estruturas e funções. Dessa maneira, para facilitar a demonstração do pareamento das bases, os professores propuseram que elas fossem representadas com cores diferentes no MD. Mesmo assim, percebeu-se que os estudantes fizeram combinações errôneas. Nesse momento, foi possível trabalhar conceitos de mutações gênicas, que podem modificar a proteína sintetizada. Em alguns casos, essas alterações são deletérias para o organismo, já em outros mais raros, oferecem vantagens adaptativas ao indivíduo, podendo passar às suas proles, levando à processos evolutivos.

Observou-se que os alunos tinham pouco conhecimento sobre o que representa o nucleotídeo na estrutura do material genético. Dessa forma, durante a aula procurou-se demonstrar que os nucleotídeos, comparados a "tijolos", são inúmeras unidades que formam tanto o DNA como o RNA. Com essa analogia, os estudantes compreenderam melhor, o que facilitou o processo de ensino-aprendizagem. Com relação ao gene, boa parte dos alunos reconhecem que o ele está relacionado com as características do indivíduo, mas não souberam explicar como o gene se encontra no DNA. Isso mostra que os discentes têm dificuldade de visualizar a posição dos genes na macromolécula. Esta dificuldade provavelmente ocorre devido à genética molecular ser um assunto abstrato, carecendo de alternativas didáticas que possam demonstrar simulações de como isso acontece na realidade. Nesse quesito, o MD de DNA possibilitou representar na prática o que seria o gene.

Após os grupos explicarem os termos trabalhados para os alunos da $1^{\text {a }}$ série do Ensino Médio, percebeu-se que houve satisfação com a experiência vivenciada. Dessa maneira, $91 \%$ dos alunos responderam que gostaram de ter confeccionado o MD de DNA, $8 \%$ disseram que mais ou menos e $1 \%$ disse que não gostou. Outro fato curioso, é que $95 \%$ responderam que nunca desenvolveram atividade similar em Biologia e 5\% não lembravam. Segundo suas respostas, $92 \%$ afirmaram gostar de fazer a explicação dos termos aos colegas de outra série, 5\% disseram que mais ou menos e 3\% que não gostaram (Figura 2). Isso demonstrou que a atividade de construção de MD e a explicação feita para colegas de outra turma, foi proveitosa para a maioria, mas houve aqueles que não gostaram, provavelmente porque são mais tímidos e tem algum tipo de dificuldade para realizar apresentação. Mesmo assim, acredita-se que esse exercício pode ter colaborado para o desenvolvimento da oratória dos estudantes. 
Figura 2 - Percentual das repostas dos alunos do $3^{a}$ Série do Ensino Médio, da Unidade Escolar Saturnino Moura, às perguntas: A - Você gostou de confeccionar o modelo didático? B - Você já desenvolveu atividade similar em Biologia? C Você gostou de explicar para os colegas de outra série?
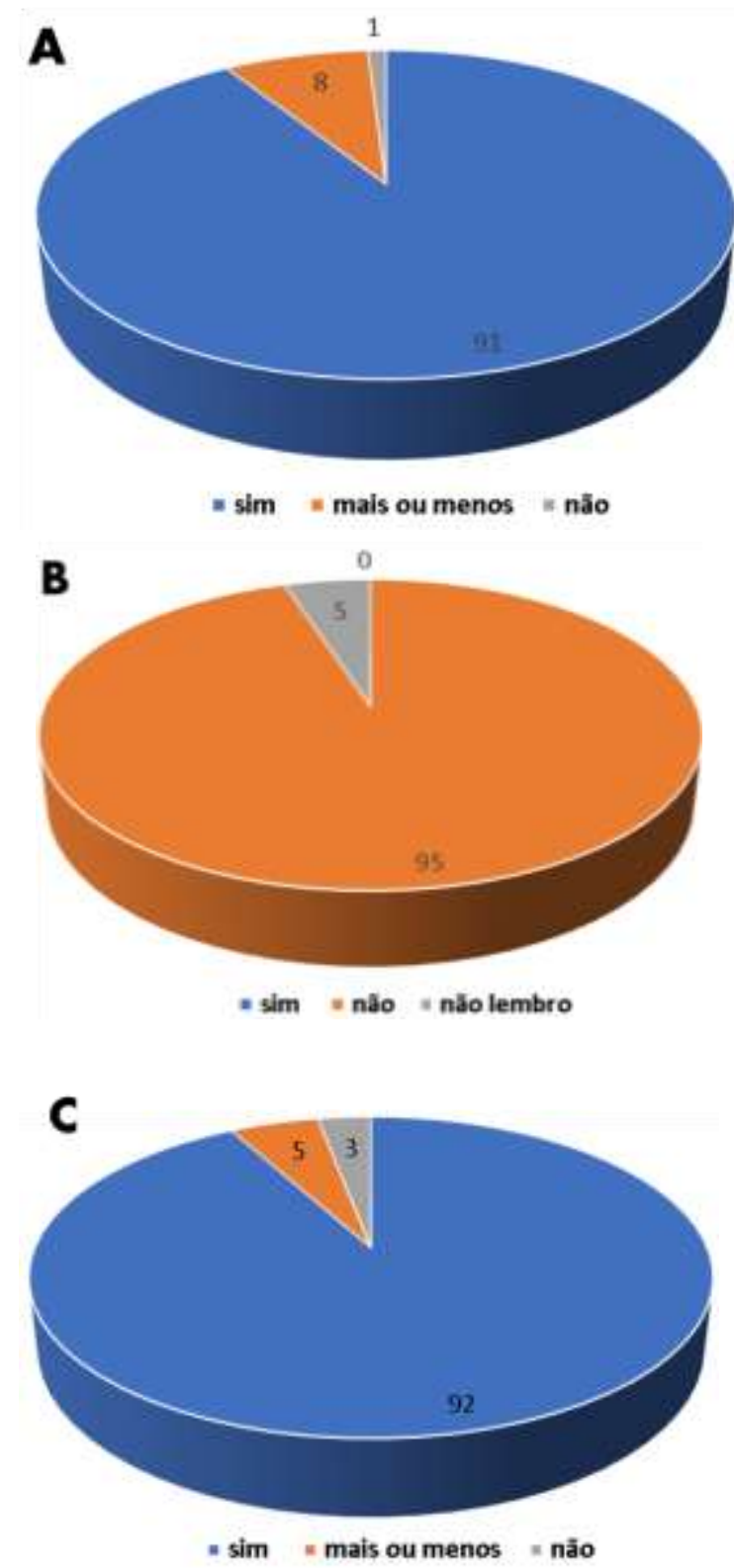

Fonte: Autores (2020).

Quanto a opinião sobre a atividade realizada, todos os estudantes acharam interessante e reconhecem o potencial do uso de MD no processo de ensino-aprendizagem, destacando-se depoimentos como: "Eu gostei de tudo, a elaboração da atividade permitiu aprender muita coisa, eu já tinha visto o DNA na $1^{a}$ série do Ensino Médio, mas não lembrava mais de nada", outro aluno respondeu que: "A confecção do modelo foi muito legal, a gente se divertiu bastante, deu para entender várias coisas. Explicar para os alunos da $1^{\mathrm{a}}$ série foi muito bom, porque parece que eu consegui aprender mais”, um terceiro aluno disse: "Eu gostei muito de explicar o assunto, eles ficaram curiosos e com inveja, isso foi legal porque a gente percebe que ensinar me ajudou a fixar melhor o assunto. Acho que nunca vou esquecer dessa experiência." 


\section{Discussão}

De acordo com Sousa et al. (2014), o método tradicional de ensino, com aulas expositivas teóricas, ainda prevalece na prática docente de muitos professores, o que torna as aulas monótonas e pouco atraentes para os alunos. Além disso, os educadores acabam deixando o caráter inovador de lado, pois muitas escolas têm carências até mesmo de recursos didáticos básicos para a realização das aulas, o que pode desmotivar os professores e dificultar o desenvolvimento de metodologias e recursos didáticos. Contudo, os educadores precisam romper essas barreiras, a fim de promover aulas mais dinâmicas e interativas, de forma a contribuir para a aprendizagem de conceitos complexos e abstratos como os encontrados em genética.

Em referência a isso, Brito et al. (2020) afirmam que somente a aula expositiva não constitui uma metodologia de ensino eficaz, devendo-se acrescentar atividades práticas complementares. Por isso, fomentar o uso de MD, como o que foi utilizado neste trabalho, para ensinar temáticas e conteúdos científicos de difícil assimilação pelos alunos, não pode ser concebido como uma iniciativa técnica e isolada (Guerra, Dalmaso \& Shetinger, 2020). Uma vez que a realização de atividades práticas e aulas experimentais proporcionam melhor resultado no aprendizado. Isto, se deve ao fato de os alunos demonstrarem maior interesse e curiosidade nos mecanismos que inter-relacionam teoria e prática (Silva, 2018; Nascimento et al., 2020). Isso pode ser notado nesse trabalho, em que os alunos realizaram pesquisas no livro didático para entender os conceitos estudados e o MD contribuiu para a aprendizagem significativa dos conteúdos de genética.

Segundo Lima et al. (2020), a utilização de MD sobre o ciclo celular melhorou a participação de estudantes da educação básica. Esses autores consideram que as metodologias ativas aplicadas foram satisfatórias e tiveram aceitação dos alunos, além de melhores desempenhos no questionário pós-teste. Diante disso, Silva \& Saraiva (2020) destacam que metodologias de ensino, que colocam o aluno em uma posição ativa, vão de encontro ao que propõe a BNCC, com participação dos estudantes no processo de ensino-aprendizagem.

Para Moran (2018), quando o aluno se envolve na aula, sente-se motivado e encontra sentido nas atividades propostas, tornando o aprendizado significativo. A adoção de métodos de ensino alternativos como: os jogos, modelos didáticos, as aulas práticas e experimentais, permitem trabalhar os conceitos de genética no Ensino Médio, de maneira que possam instigar o interesse dos educandos e contribuir para compreensão de fenômenos biológicos. É uma prática que merece ser difundida para o aprimoramento do processo de ensino (Schneider et al., 2011; Silva \& Fontes, 2018; Silva, 2019; Roque, Will \& Caetano, 2020). Tal fato foi notado neste estudo, com a utilização dos MD para trabalhar os conceitos de genética.

Os depoimentos dos estudantes após a apresentação dos MD aos colegas da turma da $1^{a}$ série mostram que o uso de atividades como a realizada neste estudo, permite a participação ativa do aluno no processo de ensino-aprendizagem. Essa estratégia pode ser reforçada pela teoria do psicólogo William Glasser (1925 - 2013). Ele afirma que os alunos aprendem efetivamente quando explicam aos seus colegas. Esse tipo de atividade evita que o aluno ocupe exclusivamente a posição de expectador (Sousa et al., 2014). Essa metodologia é comum na formação docente, mas pode ser utilizada no processo educativo dos estudantes, pois o aluno aprende enquanto ensina, aumentando o aprendizado.

Ao realizar aulas utilizando MD de fácil reprodutibilidade, pode-se perceber vantagens de aliar teoria à prática, garantindo assim a oportunidade para que os alunos participem ativamente nas aulas, formulando questões, expressando ideias, interagindo com os grupos e, sobretudo, buscando soluções para os problemas propostos (Rezende \& Gomes, 2018). Desse modo, percebeu-se que a utilização de MD de DNA para o ensino de genética proporcionou aos discentes, interesse e motivação pelo aprendizado. Sendo, portanto, um recurso didático útil e com valor pedagógico, produzido com materiais simples, de baixo custo e que podem ser adquiridos pelos próprios alunos. 


\section{Considerações Finais}

Após análise dos dados, constatou-se que os alunos demonstraram interesse pela atividade prática e sentiram-se motivados a realizarem pesquisas bibliográficas e leituras de conceitos relacionados ao material genético, necessários a compreensão dos conteúdos de genética. Pode-se perceber também, o envolvimento com a atividade proposta durante a confecção e demonstração do MD aos colegas da $1^{\mathrm{a}}$ série do Ensino Médio, o que pode contribuir para o processo de aprendizagem.

Diante disso, observou-se que ao ensinar o aluno aprende melhor. Sendo, portanto, uma estratégia que possibilita que o estudante se torne agente do seu próprio aprendizado. Os MD são instrumentos sugestivos e representativos que podem ser eficazes na atividade docente, além de ajudar os estudantes no entendimento de conteúdos abstratos e de difícil abordagem nas aulas de Biologia, levando-os a níveis de satisfação por terem concluído a atividade proposta, pode também, proporcionar aulas dinâmicas, facilitar a relação aluno-aluno, aluno-professor e o trabalho em equipe.

Portanto, acredita-se que o presente estudo poderá servir de suporte para trabalhos futuros, em escolas outras escolas e regiões do país, para subsidiar professores de Biologia, para que eles possam fazer uso de MD em sua prática pedagógica.

\section{Agradecimentos}

À Unidade Escolar Saturnino Moura, à professora então coordenadora Luciane Maria, pela dedicação e empenho na função de coordenadora pedagógica e ao então diretor, professor Rilson José por fornecer parte do material necessário à realização da prática. Aos alunos da turma da 3ª série do Ensino Médio, 2019.

\section{Referências}

Brasil. (2016). Resolução $N^{o} 510$ de 07 de abril de 2016. Publicada no DOU nº 98, terça-feira, 24 de maio de 2016, seção 1, páginas 44, 45, 46. Brasília: Ministério da Saúde.

Brito, M. V. et al. (2020). O uso do jogo "Caminhos da Genética" como estratégia metodológica para o ensino de genética. In Anais: Avaliação: Processos e Políticas / organizadora, Paula Almeida de Castro. - Campina Grande: Realize eventos, 2020. 3, 1940.

Corazza-Nunes, M. J. et al. (2006). Implicações da mediação docente nos processos de ensino e aprendizagem de biologia no ensino médio. Revista Electrónica de Enseñanza de las Ciências, 5(3), 522-533.

Florêncio, R. R., Santos, C. A. B., \& Oliveira, A. C. B. (2019). Métodos e Técnicas de Pesquisa em Educação. Rios Eletrônica (Fasete), 21, 36-50.

Fonseca, J. J. S. (2002). Metodologia da pesquisa científica. Fortaleza: UEC.

Guerra, L., Dalmaso, A. C., \& Schetinger, M. R. C. (2020). The use of models as tools to facilitate the teaching and learning process in the initial formation of pedagogues. Research, Society and Development, 9(8), 1-24.

Larentis, L. T., Amancio, J. da S., \& Ghisi, N. de C. (2020). Uma abordagem prática para o ensino de genética: mapas genéticos. Arquivos do Mudi, 24(1), 96106.

Lima, M. M. de O. et al. (2020). Practical Biology activities: an investigative teaching sequence about the cell cycle. Research, Society and Development, 9(9), 1-22.

Lopes, S., \& Rosso, S. (2012). Bio. Saraiva.

Lopes, S., \& Rosso, S. (2013). Bio - Volume único. (3a ed.), Saraiva.

Moran, J. M. Metodologias ativas para uma aprendizagem mais profunda (2018). In: Lilian Bacich, José Moran. (Org.). Metodologias ativas para uma educação inovadora. 1, 1-25.

Nascimento, R. G. et al. (2020). Prática lúdica 'DNA recombinante' e sua influência na percepção e no conhecimento de estudantes sobre biotecnologia e enzimas de restrição. Experiências em Ensino de Ciências, 15(20), 262-282.

Pereira, A. S. et al. (2018). Metodologia da pesquisa científica. UFSM. https://repositorio.ufsm.br/bitstream/handle/1 /15824/Lic_Computacao_MetodologiaPesquisa-Cientifica.pdf?sequence $=1$

Roque, A. A., Will, N. C., \& Caetano, L. G. (2020). On the path of gene expression: a pedagogical proposal for teaching Biology. Research, Society and Development, 9(7), 1-28. 
Research, Society and Development, v. 10, n. 2, e39610212005, 2021

(CC BY 4.0) | ISSN 2525-3409 | DOI: http://dx.doi.org/10.33448/rsd-v10i2.12005

Santana, E., Souza, C. R. T., \& Sampaio, S. F. (2017). Impactos do uso de experimentos de baixo custo no ensino de genética em colégios de ensino médio. Revista Ciências \& Ideias, 8(2), 42-56.

Schneider, E. M., Justina, L. A. D., \& Meglhioratti, F. A. (2011). A percepção de alunos do ensino médio em relação a interação gene-organismo-ambiente. In: VIII ENPEC - Encontro Nacional de Pesquisa em Educação em Ciências e I CIEC - Congreso Iberoamericano de Investigacion en Ensenanza de las Ciencias.

Silva, J. S. da, \& Fontes, L. S. da. (2018). "Combatendo os nematelmintos parasitas": jogo didático para facilitar a aprendizagem. Revista Eletrônica Ensino, Saúde e Ambiente, 10, 127-143.

Silva, J. S. da (2019). Extração de DNA de cebola (Allium cepa) por alunos de uma escola estadual de Teresina-PI, como complemento no ensino de genética. Revista Científica Semana Acadêmica, 1, 1-10.

Silva, J. S. da, \& Saraiva, E. de S. (2020). The importance of didactic sequence (SD) in environmental education: an experience report at the Monsenhor Boson Full-Time Education Center. Research, Society and Development, 9(6), 1-14.

Sousa, F. S., Silva, J. S., Paranhos, J. D. N. \& Dantas, S. M. de M. (2014). As metodologias usadas por professores de ciências e biologia no processo ensino aprendizagem. Revista da SBEnbio, 7, 2014-2022. 